\title{
Faecal shedding of campylobacteria among domestic and wild animals from an urban coastal area
}

\author{
Arturo Levican ${ }^{\mathrm{a}}$, Oriana Flores ${ }^{\mathrm{b}}$, Sergio Sanchez ${ }^{\mathrm{c}}$, María G. Bascuñan ${ }^{\mathrm{c}}$, \\ Rafael Lopez ${ }^{\mathrm{c}}$, Karla Ojedac ${ }^{\mathrm{c}}$, Eduardo Hernandez ${ }^{\mathrm{d}, \mathrm{e}}$, Pablo Salah ${ }^{\mathrm{d}, \mathrm{e}}$
}

\begin{abstract}
Campylobacter jejuni and Campylobacter coli are the leading cause of food-related diarrhea worldwide. However, other campylobacteria such as other Campylobacter spp., Arcobacter spp. and Helicobacter spp. are also recognised as emerging pathogens, although they are not frequently isolated by traditional culturing methods. Moreover, Campylobacter spp. have become increasingly resistant to antibiotics due to antibiotic usage in animal and human medicine. It has been suggested that pet ownership increases the risk for campylobacteriosis. However, environmental factors such as temperature, humidity, and poor sanitation conditions have also been associated with the highest rates of shedding among animals. This study assessed the faecal shedding of campylobacteria in an urban coastal area among $68(66.0 \%)$ domestic animals, mainly dogs $(n=61)$, and $35(33.9 \%)$ wild animals belonging to 13 species and eight orders. None of them had symptoms of gastroenteritis and campylobacteria were detected by PCR in 21 samples (20.4\%), while only six $(5.8 \%)$ were detected by culturing, i.e. Campylobacter upsaliensis $(\mathrm{n}=4, \operatorname{dogs})$, C. jejuni $(\mathrm{n}=1, \operatorname{dog})$ and Arcobacter butzleri $(\mathrm{n}=1$, chicken). None of the isolates was resistant to ciprofloxacin, but two were resistant to erythromycin, i.e. A. butzleri $(\mathrm{MIC}=8$ $\mu \mathrm{g} / \mathrm{ml}$ ) and C. upsaliensis (MIC $=128 \mu \mathrm{g} / \mathrm{ml}$ ). Regarding the virulence factors, only one isolate of $C$. jejuni was positive for $c d t C$ and $c a d F$ genes and one isolate of $A$. butzleri was positive for $c a d F$ and $c i a B$ genes. This is the first study to assess the faecal shedding of campylobacteria in animals from the urban coastal area of Valparaíso, Chile. Although C. jejuni and other emerging campylobacteria were detected mainly from pet dogs and in a low rate, further investigations are needed to assess the potential transmission of these zoonotic bacteria or their antibiotic resistance between pets and owners.
\end{abstract}

Key words: Arcobacter, Campylobacter, domestic and wild animals, Helicobacter.

\section{INTRODUCTION}

Campylobacteria is a group bacteria that share morphologic and ecologic characteristics, i.e. they are Gram negative curved rods that often colonise the digestive tract of their hosts, despite the fact that they belong to different taxonomic groups such as the genera Campylobacter, Helicobacter, Arcobacter, Lawsonia and Anaerobiospirillum (On 1996). Among them, the genera Campylobacter, Helicobacter, and Arcobacter have been more frequently associated with gastroenteritis in humans and animals (Bascuñana et al 2011, Collado and Figueras, 2011). Bacteria from the genus Campylobacter spp. have been worldwide recognised as the leading cause of acute bacterial gastroenteritis in humans (Ghosh et al 2014). The incidence rate of campylobacteriosis in the United States had been estimated in 14.3 per 100,000 population in 2012, causing approximately 1 million illnesses and

Received: 22.07.2018.

Accepted: 20.11.2018.

aTecnología Médica, Facultad de Ciencias, Pontificia Universidad Católica de Valparaíso, Valparaíso, Chile.

bInstituto de Biología, Facultad de Ciencias, Pontificia Universidad Católica de Valparaíso, Valparaíso, Chile.

'Tecnología Médica, Facultad de Medicina, Universidad Nacional Andrés Bello, Viña del Mar, Chile.

dFundación de Rescate Animal Namku, Concón, Valparaíso, Chile.

${ }^{e}$ Escuela de Medicina Veterinaria, Universidad Santo Tomás, Viña del Mar, Chile.

*Corresponding author: A Levican; Av. Universidad 330, Curauma, CP 2373223,Valparaíso, Chile; arturo.levican@pucv.cl, aalevican@gmail.com
75 deaths annually, while in Europe, 246,307 cases were reported during 2016 according to EFSA (Crim et al 2014, EFSA, 2016). The vast majority of human gastroenteritis are caused by C. jejuni $(80 \%-85 \%)$ and C. coli $(10 \%$ 15\%) (Bullman et al 2012). However, data increasingly suggest that other campylobacteria such as emerging Campylobacter spp. together with Arcobacter spp. and Helicobacter spp have been underestimated as the cause of human and animal disease for several reasons including the capacity for isolation and differentiation of the methods used (Collado et al 2013, Bascuñana et al 2011, Bullman et al 2012, Leahy et al 2017). The detection of virulence associated genes has meant a considerable progress to determine the pathogenic potential of campylobacteria. In this regard, the presence of several virulence factors have been linked to motility, adhesion capacity, cell invasion and production of cytotoxins that could explain the pathogenic capacity of campylobacteria in the gastrointestinal tract (Khoshbakht et al 2013, Levican et al 2014). There is a need to demonstrate the link between the presence of virulence factors and pathogenicity, which is key to better understand bacteriosis in order to develop and implement more effective therapies against infection (Lapierre 2013). On the other hand, a constant monitoring of antimicrobial susceptibility among Campylobacter isolates has been recommended due to the current emergence of isolates resistant to antibiotics including fluoroquinolones, tetracycline and erythromycin, which are the treatment of choice (Garcia et al 2009).

Campylobacteria infection is transmitted via direct contact with faeces or by cross contamination through 
food, as well as by raw or undercooked meat or raw milk, while the main type of food involved in relation to public health is poultry and pork (Frasao et al 2017). However, other sources of transmission that have been recognised are the consumption of contaminated water as well as the contact with a wide variety of domestic and wild animals, especially cats, dogs, cattle, sheep, pigs and birds (Tresierra et al 2006, Leahy et al 2017). In fact, pet ownership can significantly increase the risk for human Campylobacter infection, because it has been estimated that about $6 \%$ of human enteric campylobacteriosis is transmitted from pets, while these animals also represent a potential source of dissemination of antimicrobial resistance due to their close contact with humans (Rossi et al 2008).

In Latin American countries, some studies have shown variable rates between $9 \%$ and $20 \%$ of faecal shedding among domestic and wild animals (Tresierra et al 2006, Fernández et al 2011). In those studies, the highest values have been associated with a high environmental temperature and humidity and poor sanitation conditions, as well as to the possible contact between wild animals and humans or poultry (Fernández et al 2011, Tresierra et al 2006). Furthermore, the animals with the highest values have been those belonging to the orders Galliformes and Primates (Tresierra et al 2006).

Faecal shedding among domestic animals has been shown to range from $20 \%$ to $75 \%$, and such results depend not only on the detection method but also on the population of animals sampled (Leahy et al 2017). For instance, the lower end of this range corresponds to pet dogs, and the higher, to dogs in shelters or kennels. In fact, remarkable differences have been observed between studies including stray dogs or pet dogs (Toledo et al 2015).

Valparaíso region is a coastal urban area located in the center of Chile, which presents a Mediterranean Climate ${ }^{1}$. The average annual temperature in Valparaíso is $58.0^{\circ} \mathrm{F}$ $\left(14.4^{\circ} \mathrm{C}\right)$, ranging from $64.0^{\circ} \mathrm{F}\left(17.8^{\circ} \mathrm{C}\right)$ in January to $53.0^{\circ} \mathrm{F}\left(11.7^{\circ} \mathrm{C}\right)$ in July, while the average annual amount of precipitation is $19.9^{\prime \prime}(505.5 \mathrm{~mm})^{1}$. Considering that no previous studies on Campylobacter or other emerging campylobacteria have been conducted in this geographic region, the aim of this study is to determine the prevalence of faecal shedding of these zoonotic bacteria of public health concern among domestic and wild animals from the Valparaíso region (Chile) and to determine the presence of potential virulence factors and/or antibiotic resistance among the isolates.

\section{MATERIAL AND METHODS}

\section{SAMPLE COLLECTION}

A total of 103 faecal samples from domestic and wild animals were collected between September and November 2016 (table 1). Domestic animals corresponded to pets hospitalised at the Santo Tomás Veterinary Clinical Hospital, Valparaíso, Chile. The wild animals analysed were those treated at the Animal Rescue Foundation Namku, Concón, Valparaíso, Chile ${ }^{2}$. This foundation is dedicated to recover the health conditions of wild animals that have been rescued from risk situations generated by humans. All animals were sampled upon arrival to their respective center. However, all of those animals that had been treated with antimicrobials, as well as those that did not shed stools or present difficulty in issuing depositions, were excluded from this study. This study was approved by the ethics committee of the Medical Faculty of the Universidad Andrés Bello, Chile.

The samples corresponded to animal fresh depositions shed by spontaneous evacuation during the time established for their collection, considering only one sample per animal regardless of the time they stay in the center. The animals were not handled directly and the whole procedure was carried out with the help and supervision of the personnel in charge of the animals. For collection, clean plastic films were placed in the floor of the cage and the samples were taken using wooden sticks and deposited in clean sterile flasks for culturing immediately after issued. For DNA extraction, an aliquot of stools was deposited into a tube containing RNA later ${ }^{\mathrm{TM}}$ (Sigma, USA) and stored refrigerated at $4{ }^{\circ} \mathrm{C}$, as recommended by Gray et al (2012). RNA was used later because it has performed as a good DNA preservation method, preserving DNA in samples refrigerated for at least 1 month with the added benefit of lower PCR inhibition (Gray et al 2012). Afterwards, samples were transported and then processed for culturing on the same day, while for DNA extraction, samples were stored refrigerated and processed weekly.

\section{BACTERIAL DETECTION AND IDENTIFICATION}

For the direct bacterial detection from faeces by PCR, total DNA was extracted from samples conserved in RNA later within the week of collection. To do this, $100 \mu \mathrm{L}$ of each sample were washed twice in phosphate buffered saline (PBS) pH 7.4, 0.01 M (Winkler, Chile). DNA was then extracted using the commercial kit Instagene matrix ${ }^{\circledR}$ (Biorad, USA), according to the manufacturer's instructions for bacteria. The presence of stool derived PCR inhibitors was assessed as described by Holland et al (2000). In brief, a set of ten DNA samples were randomly

\footnotetext{
2 http://namkufundacion.cl
} 
selected and used to amplify the 16S rRNA gene by using commercial kit GoTaq Green Master Mix (Promega, USA) and universal primers PA and PH in PCR reactions. The PCR products were then subjected to electrophoresis in $1 \%$ agarose gel (Sigma, USA), stained with SYBR ${ }^{\circledR}$ Safe DNA Gel Stain (Thermo Fisher, USA) and visualised in UV transilluminator. As the ten samples yielded a strong positive amplicon, no inhibition was assumed.

The samples were submitted to genus-specific PCR for Campylobacter (Linton et al 1996), Arcobacter (Harmon and Wesley 1997), and Helicobacter (Moyaert et al 2008), using the commercial kit GoTaq Green Master Mix (Promega, USA) with the concentrations of primers and conditions indicated by their respective authors (table $\mathrm{S} 1)^{3}$. In the case of samples positive for genera Campylobacter and Arcobacter, a second PCR was carried out for the detection of specific species associated with human infections: $C$. jejuni, C. coli, C. ureolyticus, C. upsaliensis, $C$. concisus, $A$. butzleri and A. cryaerophilus (Bullman et al 2012, Collado et al 2013, Figueras et al 2014) (Table S1). In all cases, PCR products were then subjected to electrophoresis in $1 \%$ agarose gel (Sigma, USA), stained with SYBR $®$ Safe DNA Gel Stain (Thermo Fisher, USA) and visualized in UV transilluminator.

For culturing, samples were directly seeded onto Campylobacter Charcoal Deoxycholate Agar supplemented with Cefoperazone and Amphotericin B (CCDA, Liofilchem, Italy), and incubated for $48 \mathrm{~h}$ to $72 \mathrm{~h}$ at $37^{\circ} \mathrm{C}$ under microaerobic conditions $\left(\sim \mathrm{O}_{2} 5-7 \%, \mathrm{CO}_{2} 5-10 \%\right.$, $\mathrm{N}_{2} 85 \%, \mathrm{H}_{2} 3 \%$ ) using the Anaerocult $\mathrm{C}$ ( (Merck, USA) generator system into an appropriate anaerobic jar. Presumptive colonies of campylobacteria were submitted to Gram stain to observe the characteristic morphology (Gram negative curved or s-shaped rods) and re-streaked on Trypticase Soy Agar supplemented with 5\% sheep blood (BA) and incubated as described above.

\section{PHENOTYPIC AND MOLECULAR CHARACTERISATION}

Phenotypic characterisation of these colonies was carried out by using biochemical tests including catalase, oxidase, hydrolysis of hippurate, and susceptibility to nalidixic acid and cefalotin (Table S2) as described by Fernández et al (2016).

For the molecular characterisation, total DNA was extracted from the isolated colonies with the Instagene Matrix ${ }^{\mathrm{TM}}$ (Biorad, USA) kit according to the instructions of the manufacturer. Genus and species specific molecular identification of this colonies were carried out as described above. The presence of potential virulence associated genes was determined by PCR in all of the isolates identified as Campylobacter spp. or Arcobacter spp. The tested genes were selected on the basis of their prevalence in previous

\footnotetext{
Available at: www.australjvs.cl/ajvs
}

studies as well as on their putative role in pathogenesis for Campylobacter spp. (cadF, associated with adhesion and cell invasion; iamA, invasion associated marker; pldA, phospholipase A associated with lysis of erythrocytes; $c d t A$, $c d t B$ and $c d t C$, encoding the subunits $\mathrm{A}, \mathrm{B}$ and $\mathrm{C}$ of the Citolethal Distending Toxin) and Arcobacter spp. (cj1349, encoding a fibronectin binding protein implicated in adhesion; $c a d F$, associated with adhesion and cell invasion; $c i a B$, encoding a putative invasion protein) (Khoshbakht et al 2013, Levican et al 2013). PCR reactions were carried out using the commercial kit GoTaq Green Master Mix (Promega, USA), with the concentrations of primers and conditions described in the literature (Khoshbakht et al 2013, Levican et al 2013) (table S2) ${ }^{4}$. The PCR products were then subjected to electrophoresis in $1 \%$ agarose gel (Sigma, USA), and then stained with SYBR® Safe DNA Gel Stain (Thermo Fisher, USA) and visualised in UV transilluminator. The control strains used in all the phenotypic and molecular tests were the type strains of $C$. jejuni subsp. jejuni DSM $4688^{\mathrm{T}}\left(=\mathrm{ATCC} 33560^{\mathrm{T}}\right)$, C. coli DSM $4689^{\mathrm{T}}\left(=\right.$ ATCC $\left.33559^{\mathrm{T}}\right)$, and A. butzleri LMG $10828^{\mathrm{T}}$.

The susceptibility to antimicrobials was carried out with the Kirby-Bauer method using the MH-F medium (Müeller Hinton Agar supplemented with 5\% defibrinated horse blood and $\beta$-NAD $20 \mathrm{mg} / \mathrm{L}$, Liofilmchem, Italy) for ampicillin, amoxicillin/clavulanic acid, gentamicin, ciprofloxacin, nalidixic acid, erythromycin, azithromycin, and tetracycline, using the strain $C$. jejuni subsp jejuni DSM $4688^{\mathrm{T}}\left(=\right.$ ATCC $\left.33560^{\mathrm{T}}\right)$ as control. All plates were incubated at $37^{\circ} \mathrm{C}$ for 48 hours under microaerophilic conditions $\left(\sim \mathrm{O}_{2} 5-7 \%, \mathrm{CO}_{2} 5-10 \%, \mathrm{~N}_{2} 85 \%, \mathrm{H}_{2} 3 \%\right)$ using the Anaerocult ${ }^{\circledR} \mathrm{C}$ (Merck, USA) generator system into an appropriate anaerobic jar. In parallel, the minimum inhibitory concentration (MIC) was determined by the double dilution in agar method from $0.125 \mu \mathrm{g} / \mathrm{mL}$ to 256 $\mu \mathrm{g} / \mathrm{mL}$, for erythromycin and ciprofloxacin as previously described (Fernández et al 2016). Cut offs for interpretation of Kirby-Bauer and MIC results were obtained from the recommendations of the Comité de l'Antibiogramme of the Société Française de Microbiologie (2017).

\section{RESULTS}

A total of 103 samples were collected, of which 74 (71.8\%) were obtained from domestic animals, mainly dogs ( $\mathrm{n}=61)$. On the other hand, $29(28.2 \%)$ wild animals were sampled which belonged to 13 species and eight orders (table 1). None of these animals had symptoms of gastroenteritis.

Overall, 21 samples were PCR-positive to Campylobacter spp. $(\mathrm{n}=8,38.1 \%)$, Helicobacter $\mathrm{spp} .(\mathrm{n}=8,38.1 \%)$, and Arcobacter $\mathrm{spp} .(\mathrm{n}=5,23.8 \%)$. Among the Campylobacter species, C. upsaliensis $(\mathrm{n}=4,50 \%), C$. jejuni $(\mathrm{n}=1,12.5 \%)$,

4 Available at: www.australjvs.cl/ajvs 
and $C$. coli $(\mathrm{n}=1,12.5 \%)$, were identified, while only $A$. butzleri $(\mathrm{n}=1,20 \%)$ was identified among Arcobacter spp. positive samples. Animals belonging to four species were positive for campylobacteria tested by genus specific PCR, i.e. domestic dog (Canis lupus familiaris, Order Carnivora), chicken (Gallus gallus domesticus, Order Galliformes), Southern sea lion (Otaria flavescens, order Carnivora), and Magellanic penguin (Spheniscus magallanicus, Order Spheniciformes). Only six samples (5.8\%) were positive for campylobacteria by culturing, which corresponded to five Campylobacter and one Arcobacter (table 2). The predominant species isolated was $C$. upsaliensis $(\mathrm{n}=4)$ from dog faeces (table 1).

The PCR detection of virulence-associated genes demonstrated the presence of only the $c d t C$ and $c a d F$ genes in the $C$. jejuni 191101 isolate recovered from dog, and the $c i a B$ and $c a d F$ genes in the A. butzleri 191103 isolate from chicken, while all other isolates were negative for all tested genes.

All isolates were susceptible to ciprofloxacin, while one isolate of $C$. upsaliensis (261004) isolated from dog was resistant to erythromycin $(\mathrm{MIC}=128 \mu \mathrm{g} / \mathrm{mL})$, azithromycin, amoxicillin-clavulanic acid and tetracycline, and the remaining Campylobacter isolates were susceptible to all antimicrobials tested (table 3 ). On the other hand, the $A$. butzleri isolate (191103) from chicken also showed resistance to erythromycin $(\mathrm{MIC}=8 \mu \mathrm{g} / \mathrm{mL})$.

\section{DISCUSSION}

The faecal shedding of campylobacteria observed in wild animals $(3 / 29,10.3 \%)$ and domestic animals $(18 / 74$, $24.3 \%$ ) was relatively low considering previous studies in different animals in South America and other geographic locations (Fernández et al 2011). Regarding wild animals, our study included individuals belonging to 13 species from eight orders which mainly corresponded to birds, and among them, only two southern sea lions and a Magellanic penguin were PCR-positive for campylobacteria (table 1). A previous study on faecal shedding of Campylobacter in wild animals from the Peruvian Amazon region obtained a $11 \%$ of shedding by culturing, the main source being the orders of Galliformes and Primates (Tresierra et al 2006). The positivity found in that study was explained

Table 1. Campylobacteria detected in faeces of domestic and wild animals by PCR and culturing.

\begin{tabular}{|c|c|c|c|c|c|}
\hline Species & Order & Common name & $\mathrm{n}(\%)$ & $\begin{array}{l}\text { Direct detection } \\
\text { by PCR (n) }\end{array}$ & $\begin{array}{c}\text { Detection } \\
\text { by culturing (n) }\end{array}$ \\
\hline \multicolumn{6}{|l|}{ Domestic animals $(n=74)$} \\
\hline Canis lupus familiaris & Carnivora & Domestic dog & $61(59.2)$ & $\begin{array}{c}\text { C. upsaliensis (4); } \\
\text { C. jejuni (1) } \\
\text { Campylobacter spp. (2) } \\
\text { Arcobacter spp. (3) } \\
\text { Helicobacter spp. (5) }\end{array}$ & $\begin{array}{l}\text { C. upsaliensis (4) } \\
\text { C. jejuni (1) }\end{array}$ \\
\hline Felis silvestris catus & Carnivora & Domestic cat & $7(6.8)$ & & \\
\hline Gallus gallus domesticus & Galliformes & Chicken & $6(5.8)$ & $\begin{array}{c}\text { A. butzleri }(1) \\
\text { Helicobacter } \text { spp.(2) }\end{array}$ & A. butzleri (1) \\
\hline \multicolumn{6}{|l|}{ Wild animals $(n=29)$} \\
\hline Otaria flavescens & Carnivora & Southern sea lion & $2(1.9)$ & $\begin{array}{c}\text { A. butzleri }(1) \\
\text { Helicobacter } \text { spp.(1) }\end{array}$ & \\
\hline Bubo virginianus & Strigiformes & Magellanic horned owl & $6(5.8)$ & & \\
\hline Glaucidium nanum & Strigiformes & Austral pygmy owl & $1(1.0)$ & & \\
\hline Tyto alba & Strigiformes & Barn owl & $2(1.9)$ & & \\
\hline Spheniscus magallanicus & Sphenisciformes & Magellanic penguin & $3(2.9)$ & C. $\operatorname{coli}(1)$ & \\
\hline Anas platyrhynchos & Anseriformes & Mallard & $5(4.9)$ & & \\
\hline Larus dominicanus & Charadriiformes & Pacific gull & $3(2.9)$ & & \\
\hline Vanellus chilensis & Charadriiformes & Southern lapwing & $1(1.0)$ & & \\
\hline Vultur gryphus & Accipitriformes & Andean condor & $2(1.9)$ & & \\
\hline Geranoaetus polyosoma & Accipitriformes & Red backed owl & $1(1.0)$ & & \\
\hline Milvago chimango & Falconiformes & Chimango caracara & $1(1.0)$ & & \\
\hline Falco peregrinus & Falconiformes & Peregrin falcon & $1(1.0)$ & & \\
\hline Turdus falcklandii & Passeriformes & Austral thrush & $1(1.0)$ & & \\
\hline Total (\%) & & & $103(100 \%)$ & $21(20 \%)$ & $6(5.8 \%)$ \\
\hline
\end{tabular}


Table 2. Phenotipic and molecular identification of campylobacteria isolated in this study.

\begin{tabular}{ccccccc}
\hline Isolate & Catalase & Oxidase & Hypurate & Nalidixic acid & Cefalotin & $\begin{array}{c}\text { Species id. } \\
\text { by PCR }\end{array}$ \\
\hline 261004 & - & + & - & $\mathrm{R}$ & $\mathrm{S}$ & C. upsaliensis \\
071104 & - & + & - & $\mathrm{R}$ & $\mathrm{S}$ & C. upsaliensis \\
181111 & - & + & - & $\mathrm{R}$ & $\mathrm{S}$ & C. upsaliensis \\
181108 & - & + & - & $\mathrm{R}$ & $\mathrm{S}$ & C. upsaliensis \\
191101 & + & + & + & $\mathrm{S}$ & $\mathrm{R}$ & C. jejuni \\
$191103^{\mathrm{a}}$ & - & + & - & $\mathrm{R}$ & $\mathrm{R}$ & A. butzleri \\
Control & + & + & + & $\mathrm{S}$ & $\mathrm{R}$ & C. jejuni \\
\hline
\end{tabular}

$\mathrm{R}=$ Resistant, $\mathrm{S}=$ Susceptible

aThe strain 191103 was isolated from chicken while all others were isolated from dogs.

Table 3. Antimicrobial susceptibility of the isolates recovered in this study.

\begin{tabular}{lcccccc}
\hline & $\begin{array}{c}\text { C. upsaliensis } \\
261004\end{array}$ & $\begin{array}{c}\text { C. upsaliensis } \\
071104\end{array}$ & $\begin{array}{c}\text { C. upsaliensis } \\
181111\end{array}$ & $\begin{array}{c}\text { C. upsaliensis } \\
181108\end{array}$ & $\begin{array}{c}\text { C. jejuni } \\
191101\end{array}$ & $\begin{array}{c}\text { A. butzleri } \\
191103\end{array}$ \\
\hline $\begin{array}{l}\text { Kirby-Bauer method } \\
\text { Erythromycin }\end{array}$ & $\mathrm{R}$ & $\mathrm{S}$ & $\mathrm{S}$ & $\mathrm{S}$ & $\mathrm{S}$ & $\mathrm{R}$ \\
$\begin{array}{l}\text { Ciprofloxacin } \\
\text { Gentamicin }\end{array}$ & $\mathrm{S}$ & $\mathrm{S}$ & $\mathrm{S}$ & $\mathrm{S}$ & $\mathrm{S}$ & $\mathrm{S}$ \\
Tetracyclin & $\mathrm{S}$ & $\mathrm{S}$ & $\mathrm{S}$ & $\mathrm{S}$ & $\mathrm{S}$ & $\mathrm{S}$ \\
Amoxicilin/Clavulanic acid & $\mathrm{R}$ & $\mathrm{S}$ & $\mathrm{S}$ & $\mathrm{S}$ & $\mathrm{S}$ & $\mathrm{S}$ \\
Azithromicin & $\mathrm{R}$ & $\mathrm{S}$ & $\mathrm{S}$ & $\mathrm{S}$ & $\mathrm{S}$ & $\mathrm{S}$ \\
MIC $(\mu \mathrm{g} / \mathrm{mL})$ & $\mathrm{R}$ & $\mathrm{S}$ & $\mathrm{S}$ & $\mathrm{S}$ & $\mathrm{S}$ & $\mathrm{S}$ \\
Erythromycin & & & & & & \\
Ciprofloxacin & 128 & 1 & 1 & 2 & 1 & 8 \\
\hline
\end{tabular}

$\mathrm{R}=$ Resistant, $\mathrm{S}=$ Susceptible.

by the high temperature and humidity as well as poor sanitation conditions in the peri-urban areas were the animals sampled live (Tresierra et al 2006). Considering this, the lower temperature and humidity present in the urban coastal area where this study was conducted could explain the lower incidence observed. Regarding campylobacteria shedding in penguins and sea lions, C. coli, A. butzleri and Helicobacter spp. were the species detected in the present study. Campylobacter spp. has already been detected from marine mammals and seabirds in Antarctic and subantarctic region. However, the species most commonly reported corresponded to $C$. lari or related species (García-Peña et al 2010, 2017). In studies conducted in Europe, the overall detection of Campylobacter among wild animals has ranged from $6 \%$ to $43 \%$ and the differences have been attributed mainly to the feeding habits, diet, and preferred habitats, but also to other factors such as migration patterns, lifespan, or differerent life stages like breeding, migration, molting and wintering (Waldenstrom et al 2002, Antilles et al 2013, Krawiec et al 2017). In this same line, it has been highlighted that those animals living or feeding at watery habitats such as water edges or in shallow waters of habitats that commonly harbour Campylobacter spp. may present a high overall prevalence (Waldenstrom et al 2002).

Most of wild animals sampled here corresponded to raptors and scavenging birds admitted at the Animal Rescue Foundation Namku, Valparaíso (Chile) which were all negative for campylobacteria. On the contrary, MolinaLopez et al (2014), studied the presence of Campylobacter spp. and Salmonella spp. among faecal samples of 121 raptors admitted to the Wildlife Rehabilitation Centre of Torreferrusa (Spain), and 9 out of them (7.4\%) were positive for Campylobacter spp., demonstrating that these bacteria as well as other enteropathogens may be present in the wildlife admitted to rehabilitation centres, therefore, their zoonotic risk for the staff and general population must be considered (Molina-Lopez et al 2014).

It should be noted that due to the difficulty in the access to this kind of samples, the present study included only a few individuals of the different species sampled and this could explain the low prevalence observed. Therefore, further studies aimed to clarify whether this is the true tendency for faecal shedding of campylobacteria among animals in 
this geographical zone and to determine the factors behind this tendency are needed. Despite of this, the presence of stool derived PCR inhibitors after the extraction process was not observed in this study. Moreover, sampling was performed once for each animal and upon their arrival to the veterinary clinical or rescue foundation. Thus, cross contamination with campylobacteria due to their contact with humans or other animals was avoided. However, another limitation of this study is that the sensitivity of PCR methods used was not determined. Therefore, we are not able to state whether negative samples are due to the absence of campylobacteria or they are negative due to a bacterial load in the sample which was under the detection limit of the method.

The faecal shedding among domestic animals (24.3\%) was also low, but in previous studies it ranged from $20 \%$ to $75 \%$ depending on the detection method and on the population sampled (Leahy et al 2017). The low end of this range (20\%) corresponds to pet dogs, while the high end $(75 \%)$ corresponds to dogs in shelters or kennels (Leahy et al 2017). In fact, remarkable differences have been observed between studies including stray dogs or pet dogs (Toledo et al 2015). Therefore, it is possible that the overall low prevalence of campylobacteria among pets in this study could also be due to the fact that they belong to known owners who provide them good standards of care.

By culturing, a lower isolation rate (5.8\%) in comparison with PCR detection was obtained. Moreover, Helicobacter spp. were not isolated, even though they were detected by PCR in 3 animals. The lower performance of culturing could be attributed to the overgrowth of accompanying bacteria that hampered the recognition of campylobacteria, as well as the possible presence of Viable But Non-Culturable bacteria (VBNC) as suggested by Bullman et al (2012).

Only isolates belonging to Campylobacter spp. and Arcobacter spp. were obtained and, as expected, C. upsaliensis was the most commonly isolated species from dogs (Rossi et al 2008, Leahy et al 2017). Although the role of this species as human pathogen is not clearly established, in some cases it was associated with gastroenteritis (Holmerg et al 2015). Moreover, its prevalence among humans could have been underestimated due to the fact that methods used in the public health laboratories have been developed to detect $C$. jejuni and $C$. coli (Holmerg et al 2015). Regarding the major pathogen $C$. jejuni, the isolate 191101 of this species was recovered from a dog, confirming that pets could be a reservoir for this species. As previously suggested, $C$. jejuni could be transmitted to dogs by a food source or by their owner and there is a need for further study on this (Tamborini et al 2012). On the other hand, evidence suggests that the transmission of C. jejuni from dogs to humans can also occur through the contact with faeces of infected dogs, therefore, its shedding represents a potential threat to public health (Tamborini et al 2012, Leahy et al 2017).
The presence of potential virulence associated genes was determined by PCR in all of the isolates of Campylobacter spp. and Arcobacter spp. Only the $c d t C$ and $c a d F$ genes were detected in the $C$. jejuni isolated from dog and the $c i a B$ and $c a d F$ genes in the A. butzleri isolated from chicken. Both species have been associated with gastroenteritis in humans, therefore, it was expected the presence of putative virulence genes. On the contrary, it is possible that negative results for the other tested genes were due to differences in DNA sequences of those genes among strains because the primers have been designed on the basis of the representative strains $C$. jejuni 81-176 and A. butzleri RM4018 (Levican et al 2013, Iglesias-Torrens et al 2018). In this regard, Iglesias-Torrens et al (2018) have observed a higher diversity of $c d t A$ alleles among $C$. jejuni strains found in wild birds compared to broilers or humans. The authors hypothesize that these differences among sequences of certain $c d t$ alleles could be linked to the ability to colonize different hosts.

None of the isolates obtained in this work was resistant to ciprofloxacin, even though a resistance to this antibiotic has been previously observed among isolates from animals and humans (Garcia et al 2010, Carbonero et al 2012, Toledo et al 2015, Lapierre et al 2016). On the contrary, two isolates were resistant to erythromycin, i.e. A. butzleri 191103 (MIC=8 $\mu \mathrm{g} / \mathrm{mL}$ ) and C. upsaliensis 261004 (MIC $=128 \mu \mathrm{g} / \mathrm{mL}$ ). Moreover, the C. upsaliensis isolate was also resistant to azithromycin, amoxicillin-clavulanic acid and tetracycline. Multidrug resistance (MDR) has been previously observed among isolates from humans and broilers. However, the most frequent MDR profile has been the resistance to tetracyclyne, ciprofloxacin, naludixic acid and ampicillin, while erythromycin and gentamicin are considered the most efficient antibiotics against Campylobacter isolates from dogs (Iglesias-Torrens et al 2018). In contrast, Tsai et al (2007) observed a higher rate of resistance to azithromycin $(93.9 \%)$, clindamycin $(87.9 \%)$, erythromycin $(81.8 \%)$, tetracycline $(78.8 \%)$ and a lower rate to ciprofloxacin (18.2\%) among stray dogs from Taiwan. The authors suggested that the differences in resistance between strains from stray dogs compared with those from humans or broilers may reflect the differences in antimicrobial use between pet animal veterinary medical practice and human medical practice (Tsai et al 2007).

In conclusion, in this study it was posible to observe the shedding of $C$. jejuni and other emerging campylobacteria in faeces mainly obtained from pet dogs. This shedding was lower than that found in previous reports. Despite the fact that a low number of individuals different than dogs was sampled, the low shedding observed could be explained by different factors such as the weather conditions, and the good standards provided by their owners. However, the presence of these bacteria warrants future studies to assess the potential transmission of these zoonotic bacteria to owners, or even the transmission of the observed antibiotic resistance to other bacteria present in their microbiome. 
In this sense, under a ONE HEALTH approach, it is also necessary to design education programs aimed at owners in order to avoid this transmission of campylobacteria from pet to owners or vice versa.

\section{ACKNOWLEDGEMENTS}

The authors thank the staff at the Santo Tomás Veterinary Clinical Hospital and at the Animal Rescue Foundation Namku by their help in sample collection. This study was partially financed by Pontificia Universidad Católica de Valparaíso through grants number 039.215/2016 and DI Iniciación 039.455/2017. AL thanks Dr. Luis Collado from Universidad Austral de Chile for his support in the development of this study.

\section{REFERENCES}

Antilles N, Sanglas A, Cerdà-Cuéllar M. 2015. Free-living waterfowl as a source of zoonotic bacteria in dense wild bird population area in Northeastern Spain. Transbound Emerg Dis 62, 516-521. doi: 10.1111/tbed.12169.

Bascuñana P, Padrones I, Picazo JJ, Velasco AC. 2011. Diarrea asociada a Helicobacter pollorum en niño. Rev Esp Quimioter, 24, 50-51.

Bullman S, O'Leary J, Corcoran D, Sleator RD, Lucey B. 2012. Molecularbased detection of non-culturable and emerging campylobacteria in patients presenting with gastroenteritis. Epidemiol Infect 140, 684-688. doi: 10.1017/S0950268811000859.

Carbonero A, Torralbo A, Borge C, García-Bocanegra I, Arenas A, et al. 2012. Campylobacter spp., C. jejuni and C. upsaliensis infection associated factors in healthy and ill dogs from clinics in Cordoba, Spain. Screening tests for antimicrobial susceptibility. Comp Immunol Microbiol Infect Dis 35, 505-512. doi: 10.1016/j.cimid.2012.05.002.

Collado L, Figueras MJ. 2011. Taxonomy, epidemiology, and clinical relevance of the genus Arcobacter. Clin Microbiol Rev 24, 174-192. doi: 10.1128/CMR.00034-10.

Collado L, Gutiérrez M, González M, Fernández H. 2013. Assessment of the prevalence and diversity of emergent campylobacteria in human stool samples using a combination of traditional and molecular methods. Diagn Microbiol Infect Dis 75, 434-436. doi: 10.1016/j. diagmicrobio.2012.12.006.

Crim SM, Iwamoto M, Huang JY, Griffin PM, Gilliss D, et al. 2014 Incidence and trends of infection with pathogens transmitted commonly through food-Foodborne Diseases ActiveSurveillance Network, 10 U.S. sites, 2006-2013. Centers for Disease Control and Prevention (CDC). Morb Mortal Wkly Rep 63, 328-332.

European Food Safety Authority European Centre for Disease Prevention and Control (EFSA). 2016. The European Union summary report on trends and sources of zoonoses, zoonotic agents and food-borne outbreaks in 2016. EFSA J 15, 5077. doi: 10.2903/j.efsa.2017.5077.

Fernández H. 2011. Campylobacter y campylobacteriosis: Una mirada desde América del sur. Rev Peru Med Exp Salud Publica 28, 121-127.

Fernández H, Ochoa S, Simaluiza J. 2016. Bases metodológicas para el diagnóstico bacteriológico de las infecciones por Campylobacter. $1^{a}$ ed. Ediciones copygraph Ltda, Santiago, Chile.

Figueras MJ, Levican A, Pujol I, Ballester F. Rabada-Quilez MJ, et al. 2014. A severe case of persistent diarrhoea associated with Arcobacter cryaerophilus but attributed to Campylobacter sp. and a review of the clinical incidence of Arcobacter spp. New Microbes New Infect 2, 31-37. doi: 10.1002/2052-2975.35.

Frasao BS, Marin VA, Conte-Junior CA. 2017. Molecular detection, typing, and quantification of Campylobacter spp. in foods of animal origin. Compr Rev Food Sci Food Saf 16, 557-758. doi: 10.1111/1541-4337.12274.

García P, Valenzuela N, Rodríguez V, León E, Fernández H. 2009. Susceptibilidad antimicrobiana de Campylobacter jejuni aislado de coprocultivos en Santiago de Chile. Rev Chilena Infectol 26, 511-514. doi: 10.4067/S0716-10182009000700004.

Ghosh R, Uppal B, Aggarwal P, Chakravarti A, Jha AK, et al. 2014. A comparative study of conventional and molecular techniques in diagnosis of Campylobacter gastroenteritis in children. Ann Clin Lab Sci 44, 42-48.

Gray, MA, Pratte ZA, Kellogg CA. 2013. Comparison of DNA preservation methods for environmental bacterial community samples. FEMS Microbiol Ecol 83, 468-477. doi: 10.1111/1574-6941.12008.

Harmon KM, Wesley IV. 1997. Multiplex PCR for the identification of Arcobacter and differentiation of Arcobacter butzleri from other arcobacters. Vet Microbiol 58, 215-227.

Holland JL, Louie L, Simor AE, Louie M. 2000. PCR detection of Escherichia coli O157:H7 directly from stools: Evaluation of commercial extraction methods for purifying fecal DNA. J Clin Microbiol 38, 4108-4113.

Holmberg M, Rosendal T, Engvall EO, Ohlson A, Lindberg A. 2015. Prevalence of thermophilic Campylobacter species in Swedish dogs and characterization of C. jejuni isolates. Acta Vet Scand 57, 19. doi: 10.1186/s13028-015-0108-0.

Iglesias-Torrens Y, Miró E, Guirado P, Llovet T, Muñoz C, et al. 2018. Population structure, antimicrobial resistance, and virulence-associated genes in Campylobacter jejuni isolated from three ecological niches: Gastroenteritis patients, broilers, and wild birds. Front Microbiol 9, 1676. doi: 10.3389/fmicb.2018.01676.

Khoshbakht R, Tabatabaei M, Hosseinzadeh S, Shekarforoush SS, Aski HS. 2013. Distribution of nine virulence-associated genes in Campylobacter jejuni and $C$. coli isolated from broiler faeces in Shiraz, Southern Iran. Foodborne Pathog Dis, 10, 764-770. doi: 10.1089/fpd.2013.1489.

Krawiec M, Woźniak-Biel A, Bednarski M, Wieliczko A. 2017. Antimicrobial susceptibility and genotypic characteristic of Campylobacter spp. Isolates from free-living birds in Poland. Vector Borne Zoonotic Dis 17, 755-763. doi: 10.1089/vbz.2017.2116.

Lapierre L 2013. Factores de virulencia asociados a especies zoonóticas de Campylobacter spp. Avances en Ciencias Veterinarias 28, 25-31.

Lapierre L, Gatica MA, Riquelme V, Vergara C, Yañez JM, et al. 2016. Characterization of antimicrobial susceptibility and its association with virulence genes related to adherence, invasion and citotoxicityin Campylobacter jejuni and Campylobacter coli isolates from animals, meat, and humans. Microb Drug Resist 22, 432-444. doi: 10.1089/mdr.2015.0055.

Leahy AM, Cummings KJ, Rodríguez-Rivera LD, Hamer SA, Lawhon SD. 2017. Faecal Campylobacter shedding among dogs in animal shelters across Texas. Zoonoses Public Health 64, 623-627. doi: 10.1111/zph.12356.

Levican A, Alkeskas A, Günter C, Forsythe SJ, Figueras MJ. 2013. Adherence to and invasion of human intestinal cells by Arcobacter species and their virulence genotypes. Appl Environ Microbiol, 79, 4951-4957. doi: 10.1128/AEM.01073-13.

Linton D, Owen RJ, Stanley J. 1996. Rapid identification by PCR of the genus Campylobacter and of five Campylobacter species enteropathogenic for man and animals. Res Microbiol 147, 707-718.

Molina-Lopez RA, Valverdú N, Martin M, Mateu E, Obon E, et al. 2011. Wild raptors as carriers of antimicrobial-resistant Salmonella and Campylobacter strains. Vet Rec 168, 565. doi: 10.1136/vr.c7123.

Moyaert H, Pasmans F, Ducatelle R, Haesebrouck F, Baele M. 2008. Evaluation of $16 \mathrm{~S}$ rRNA gene-based PCR assays for genus-level identification of Helicobacter species. J Clin Microbiol 45, 18671869. doi: 10.1128/JCM.00139-08.

On SL. 1996. Identification methods for Campylobacters, Helicobacters, and related organisms. Clin Microbiol Rev 9, 405-422.

Rossi M, Hänninen ML, Revez J, Hannula M, Zanoni RG. 2008. Occurrence and species level diagnostics of Campylobacter spp., enteric Helicobacter spp. and Anaerobiospirillum spp. in healthy and diarrheic dogs and cats. Vet Microbiol 129, 304-314. doi: 10.1016/j. vetmic.2007.11.014. 
Scallan E, Hoekstra RM, Angulo FJ, Tauxe RV, Widdowson MA, et al. 2011. Foodborne illness acquired in the United States-major pathogens. Emerg Infect Dis 17, 7-15. doi: 10.3201/eid1701. P11101.

Société Française de Microbiologie. 2017. Campylobacter. In: Société Française de Microbiologie (eds). CASFM/EUCAST: Société Française de Microbiologie Recommandations du Comité de l'Antibiogramme de la Société Française de Microbiologie. Société Française de Microbiologie, Paris, France, Pp 111-114.

Tamborini AL, Casabona LM, Viñas MR, Asato V, Hoffer A, et al. 2012. Campylobacter spp.: prevalence and pheno-genotypic characterization of isolates recovered from patients suffering from diarrhea and their pets in La Pampa Province, Argentina. Rev Argent Microbiol 44, 266-271.
Toledo Z, Simaluiza RJ, Ochoa S, Fernández H. 2015. Occurrence and antimicrobial susceptibility of Campylobacter jejuni and C. coli in dog faeces from public parks in southern Ecuador. Acta Sci Vet 43,1284.

Tresierra A, Espinoza E, Bendayán M, Donayre M, Fernández H. 2006. La fauna silvestre de la Amazonía peruana, un potencial reservorio de Campylobacter jejuni subsp. jejuni y Campylobacter coli. Folia Amazónica 15, 117-122.

Tsai HJ, Huang HC, Lin CM, Lien YY, Chou CH. 2007. Salmonellae and campylobacters in household and stray dogs in northern Taiwan. Vet Res Commun 31, 931-939.

Waldenström J, Broman T, Carlsson I, Hasselquist D, Achterberg RP, et al. 2002. Prevalence of Campylobacter jejuni, Campylobacter lari, and Campylobacter coli in different ecological guilds and taxa of migrating birds. Appl Environ Microbiol 68, 5911-5917. 